\title{
Diode rectification of multiphase synchronous generators for aircraft applications
}

DOI:

10.1109/ECCE.2011.6064201

Link to publication record in Manchester Research Explorer

\section{Citation for published version (APA):}

Jordan, S., \& Apsley, J. (2011). Diode rectification of multiphase synchronous generators for aircraft applications. In IEEE Energy Conversion Congress and Exposition: Energy Conversion Innovation for a Clean Energy Future, ECCE 2011, Proceedings/IEEE Energy Conver. Congr. Expo.: Energy Conv. Innov. Clean Energy Future, ECCE, Proc. (pp. 3208-3215). IEEE. https://doi.org/10.1109/ECCE.2011.6064201

\section{Published in:}

IEEE Energy Conversion Congress and Exposition: Energy Conversion Innovation for a Clean Energy Future, ECCE 2011, Proceedings|IEEE Energy Conver. Congr. Expo.: Energy Conv. Innov. Clean Energy Future, ECCE, Proc.

\section{Citing this paper}

Please note that where the full-text provided on Manchester Research Explorer is the Author Accepted Manuscript or Proof version this may differ from the final Published version. If citing, it is advised that you check and use the publisher's definitive version.

\section{General rights}

Copyright and moral rights for the publications made accessible in the Research Explorer are retained by the authors and/or other copyright owners and it is a condition of accessing publications that users recognise and abide by the legal requirements associated with these rights.

\section{Takedown policy}

If you believe that this document breaches copyright please refer to the University of Manchester's Takedown Procedures [http://man.ac.uk/04Y6Bo] or contact uml.scholarlycommunications@manchester.ac.uk providing relevant details, so we can investigate your claim.

\section{OPEN ACCESS}


This paper was published in the Proceedings of the Energy Conversion Congress and Exposition 2011, doi 10.1109/ECCE.2011.6064201 and is available at:

URL:http://ieexplore.ieee.org/stamp/stamp.jsp?tp $=\&$ arnumber $=6064201 \&$ isnumb er $=6063732$

Jordan, S.; Apsley, J., "Diode rectification of multiphase synchronous generators for aircraft applications," Energy Conversion Congress and Exposition (ECCE), 2011 IEEE , vol., no., pp.3208,3215, 17-22 Sept. 2011

doi: 10.1109/ECCE.2011.6064201

(C) 2011 IEEE. Personal use of this material is permitted. Permission from IEEE must be obtained for all other uses, in any current or future media, including reprinting/republishing this material for advertising or promotional purposes, creating new collective works, for resale or redistribution to servers or lists, or reuse of any copyrighted component of this work in other works. 


\section{Diode Rectification of Multiphase Synchronous Generators for Aircraft Applications}

\author{
Steven Jordan \\ Power Conversion Group \\ University of Manchester \\ Manchester, UK \\ Steven.jordan@postgrad.manchester.ac.uk
}

\author{
Judith Apsley \\ Power Conversion Group \\ University of Manchester \\ Manchester, UK \\ J.apsley@manchester.ac.uk
}

\begin{abstract}
Increased electrical loading on aircraft power systems has led to interest in DC electrical networks for aircraft applications. This paper investigates a wound-field synchronous generator and uncontrolled diode rectifier as the DC source and analyses the power quality of the AC and DC sides of the rectifier. The paper gives expressions for voltage and current distortion for a multiphase generator as a function of the number of phases. For a star-connected machine, the power quality on the $\mathrm{AC}$ side is shown to deteriorate rapidly as the phase number increases, resulting in increased losses and a higher rating requirement. A delta connection provides better utilisation of the generator; however, at the expense of the fault tolerance. Mathematical models for the multiphase system are developed and the analysis is supported by simulation results; verified through laboratory testing.
\end{abstract}

\section{INTRODUCTION}

The increase in electrical loading on next generation aircraft can be attributed to the continued development of the more-electric aircraft concept, and particularly to advances in more-electric engine (MEE) technologies [1]. In order to increase the efficiency of the gas turbine cycle, pneumatic bleed air, typically taken from the high pressure (HP) spool compressor stage, can be substituted by utilising an electric generator, together with an electrical cabin pressurisation and air conditioning system. The removal of bleed air reduces the fuel burn in the gas turbine cycle and allows greater flexibility in airframe design [2].

Multiphase machines are an emerging technology with increasing research being conducted on their potential applications and inherent fault tolerance [3-5]. Civil aerospace is safety critical; therefore, the built-in redundancy of multiphase machines can be considered as advantageous for aircraft electrical power systems.

At present, $250 \mathrm{kVA}$ rated, three-phase wound-field synchronous generators are incorporated in both the RollsRoyce Trent 1000 and General Electric GEnx aero-engines to generate variable frequency power [2]. This is acceptable for standalone systems but would present problems when reconfiguring a common electrical power distribution system as the generated frequency is dependent on the speed of the engine. The ability for multiphase generator-rectifier units to provide improved DC power output is seen as beneficial in securing a move toward DC electrical networks in civil aerospace.

Utilising DC power systems at high voltages has previously been deemed unsuitable due to DC breaker technology being severely lacking. DC systems are commonly found in small commuter aircraft where $28 \mathrm{~V}_{\mathrm{DC}}$ generators supply a central busbar with DC power; this can be inverted for AC loads. However, recent advancements in superconducting fault current limiting (SFCL) devices [6] and other technologies centred on breaking HVDC in power transmission lines has led to higher voltage DC power systems for civil aerospace being considered as a near-future alternative. The approach used in more-electric shipboard power systems involving zonal DC networks fed from synchronous generators could be a future trend in aircraft [7]. The most common method of obtaining DC power from an AC source is through diode rectification, which is a simple and low cost solution. Typically, a filter capacitor is required for three-phase rectification to remove the ripple voltage; however, with an increased phase number this ripple magnitude can be reduced. This presents significant savings in weight, and reliability for aircraft applications.

Rectifier systems with more than three phases are widely used in high power DC systems, but typically use combinations of three phase systems with phase-shifting transformers to give a 12 , or 18 pulse rectifier. Modelling and analysis of these systems has focused on power quality and stability, representing the generator as ideal sources, in order to study the AC:DC conversion stage [8,9]. The symmetry arising from combinations of phase-shifted three phase systems can be used to simplify the analysis.

This paper evaluates the performance of the multiphase generator system with the aim of appraising diode rectification and, ultimately, eliminating the DC filter capacitance.

This research has been sponsored by the UK Government Engineering Physical Sciences Research Council and Rolls-Royce PLC 


\section{RECTIFIER ANALYSIS}

In an uncontrolled rectifier, the diodes turn on at positive voltage and turn off at zero current. This analysis assumes ideal switches and a constant current DC load. Under normal circuit conditions, two diodes conduct at a time, except during commutation, when the current transfers to the diodes with the highest voltage difference.

The generator can be modelled by a set of winding equations as shown below for the ' $a$ ' phase winding [10], where $n$ is an arbitrary phase. Notation is defined at the end of the paper.

$$
\begin{aligned}
& v_{a}=-i_{a} R_{s}-L_{a a}(\theta) \frac{d i_{a}}{d t}-\left(\sum_{n \neq a} L_{a n}(\theta) \frac{d i_{n}}{d t}\right) \\
& +L_{a d} \frac{d}{d t}\left[\left(i_{f}+i_{k d}\right) \cos \left(\theta-\theta_{a}\right)\right]+L_{a q} \frac{d}{d t}\left[i_{k q} \sin \left(\theta-\theta_{a}\right)\right]
\end{aligned}
$$

If the generator is at synchronous speed, with a constant rectifier current $I_{d c}$, the differential of the phase current is zero in conduction mode, and the damper currents are also zero. For a constant field current, the back emf can be represented as a sinusoidal time-varying term $e$. Neglecting the stator resistance, the voltage between the ' $a$ ' and ' $n$ ' phase windings for a star-connected machine with only two windings energized is given by (2).

$$
v_{a}-v_{n}=e_{a}-e_{n}=\hat{V}_{a c}[\sin (\omega t)-\sin (\omega t-(n-1) \gamma)]
$$

During commutation between phases ' $a$ and ' $b$ ' the equivalent circuit is as shown in Figure 1.

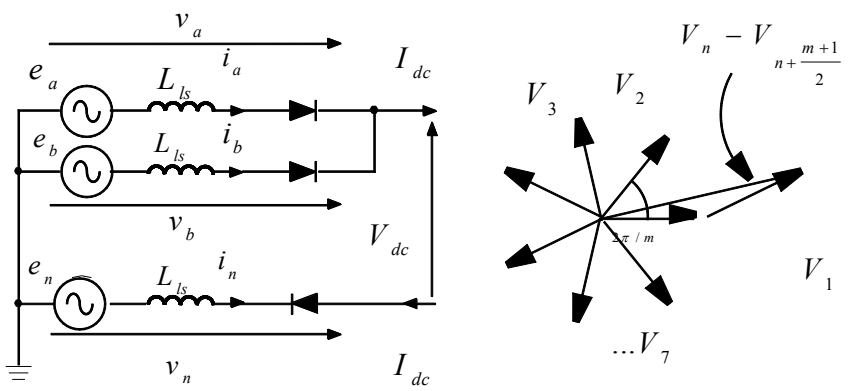

Figure 1 Generator rectifier equivalent circuit; star connection

Under this condition, the total current in the two phases supplies the rectifier current, and the diode voltage is given by the average of the two source voltages [11].

$$
v_{a}=v_{b}=\left(e_{a}+e_{b}\right) / 2
$$

The change in current is

$$
\frac{d i_{a}}{d t}=\left(e_{a}-e_{b}\right) / 2 L_{l s} \text {. }
$$

Integration over the commutation angle $\alpha$, and application of initial and final conditions gives a relationship similar to that of a three-phase rectifier,

$$
1-\cos \alpha=\frac{I_{d c} \omega L_{l s}}{\hat{E} \sin (\pi / m)}
$$

where $L_{l s}$ is the lowest inductance path in the generator. For a multiphase machine this is not the subtransient reactance, but the leakage reactance, since for balanced sinusoidal windings, the higher order $d q$ components do not link the rotor damper windings.

For $m$ ideal sinusoidal AC sources, with a phase separation of $2 \pi / m$ and a peak phase voltage $\hat{V}_{a c}$ the largest voltage difference with a star-connected generator is for phases with a separation close to $180^{\circ}$. For the delta connection, the largest voltage is given by the phasor sum of $(m \pm 1) / 2$ adjacent phase voltages and current flows in all generator phases. Figure 2 shows how the current is divided between phases as the diodes switch.
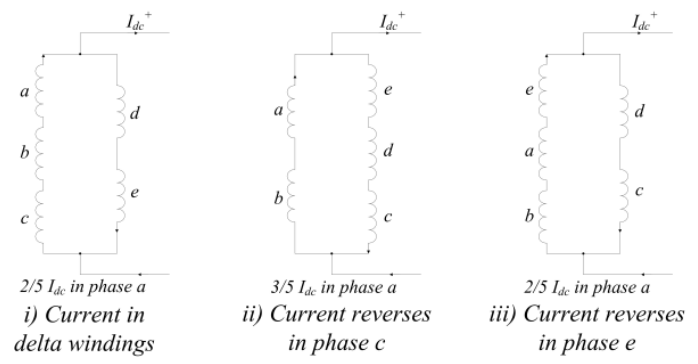

Figure 2 Conduction of current through a five-phase delta-connected machine.

The equivalent circuit for the case where phase ' $a$ ' is commutating is shown in Figure 3. The effective line inductance in the series-connected generator phases is $L_{l s}(m-1) / 2$.
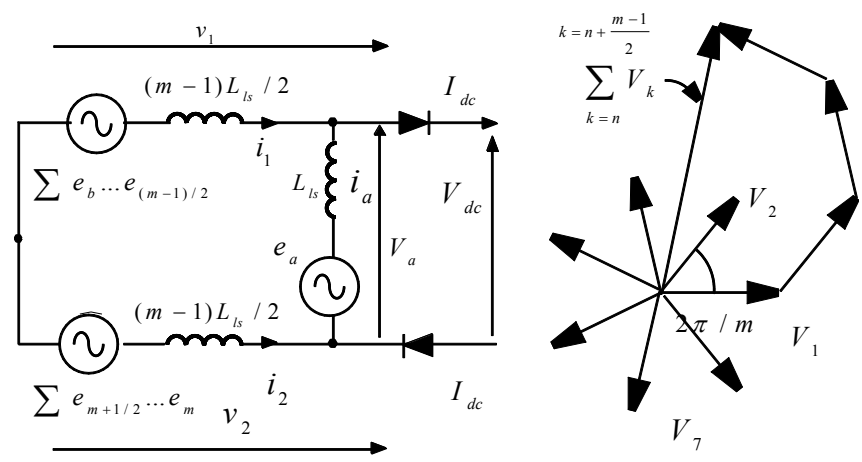

Figure 3 Generator rectifier equivalent circuit; delta connection

The relationships for DC voltages and AC currents in an uncontrolled rectifier can be derived by summing sections of the AC voltages and DC current respectively, according to which diodes are conducting. Diode commutation can be accounted for by including the voltage envelope during the period $\alpha$ when both diodes are conducting, using (5). Figure 4 shows DC link voltage (in black) following the maximum of the two line-line voltages (in red and blue), with a dip due to the commutation period from zero to $\alpha$. The DC link voltage ripple is periodic, with a period of $\pi / m$. 


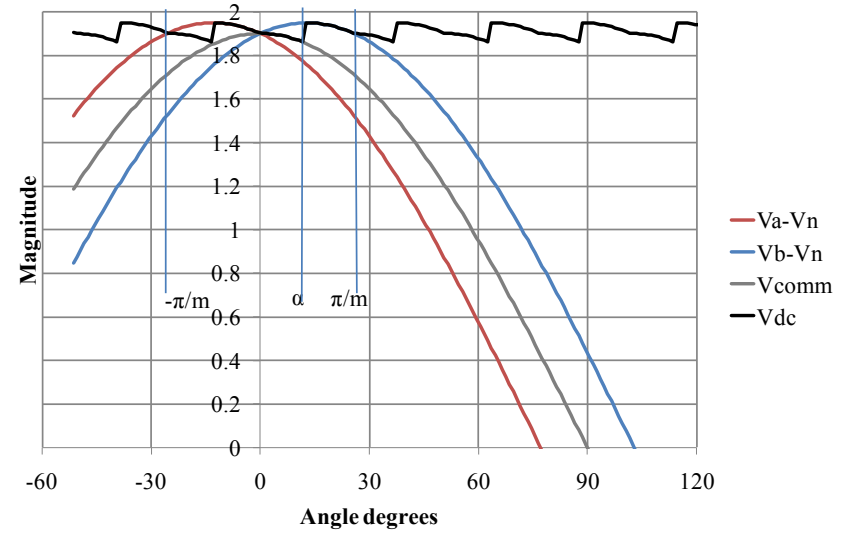

Figure 4 DC voltage waveform

With the commutation angle included, the expressions in [11] can be modified for a rectifier with more than three phases, to give the formulae in Table I. The formulae reduce to the form given in [12] for an ideal rectifier with no commutation overlap. The expressions for harmonic currents make a further simplification, approximating the rate of change of current during commutation as a constant, which modifies the magnitude of the current harmonics by a factor of $\operatorname{sinc}(\alpha / 2)$, when compared with [12].

TABLE I DC VOLTAGE AND AC CURRENT RELATIONSHIPS WITH THE GENERATOR CONNECTIONS IN STAR OR DELTA.

\begin{tabular}{|c|c|c|}
\hline & Star & Delta \\
\hline $\begin{array}{l}\text { Peak DC } \\
\text { voltage } \hat{V}_{d c}\end{array}$ & $2 \hat{V}_{a c} \sin \frac{(m-1) \pi}{2 m}$ & $\hat{V}_{a c} \frac{1}{2 \sin (\pi / 2 m)}$ \\
\hline $\begin{array}{l}\text { Commutatio } \\
\mathrm{n} \text { angle } 1- \\
\cos (\alpha)\end{array}$ & $\frac{I_{d c} \omega L}{\hat{V}_{a c} \sin (\pi / m)}$ & $\frac{I_{d c} \omega L}{\hat{V}_{a c}}$ \\
\hline $\begin{array}{l}\text { Pk-Pk DC } \\
\text { voltage }\end{array}$ & $\hat{V}_{d c}\left[1-\left(\cos \alpha \cos \frac{\pi}{2 m}\right)\right]$ & \\
\hline $\begin{array}{l}\text { Average DC } \\
\text { voltage }\end{array}$ & $\hat{V}_{d c} \frac{m}{\pi}\left(\sin \frac{\pi}{2 m}\right)(1+\cos \alpha$ & \\
\hline $\begin{array}{l}k^{\text {th }} \text { harmonic } \\
\text { DC voltage } \\
(k=2 \mathrm{~nm})\end{array}$ & $\hat{V}_{d c}(-1)^{k} \frac{2 \sqrt{2} m}{\pi} \frac{(\sin \pi}{1-}$ & $\frac{/ 2 m)}{k^{2}}$ \\
\hline $\begin{array}{l}\text { RMS AC } \\
\text { current }\end{array}$ & $I_{d c} \sqrt{2 / m}$ & $\frac{I_{d c}}{2} \sqrt{1-(1 / m)^{2}}$ \\
\hline $\begin{array}{l}k^{\text {th }} \text { harmonic } \\
\text { of } \mathrm{AC} \\
\text { current } \\
(k \neq m) R M S\end{array}$ & $\sqrt{2} I_{d c} \frac{\sin (k \pi / m)}{k \pi} \frac{\sin \alpha / 2}{\alpha / 2}$ & $2 \sqrt{2} I_{d c}\left(\frac{1}{k \pi}\right) \frac{\sin \alpha / 2}{\alpha / 2}$ \\
\hline
\end{tabular}

\section{System Simulation}

The analysis has assumed ideal sources, and neglects any transient response in other windings, due to the changing $\mathrm{AC}$ currents imposed by the rectifier. The validity of the analysis has been investigated by simulation.
Construction of a mathematical model, using the MATLAB Simulink software platform, to emulate the multiphase synchronous generator was based upon an experimentally validated three-phase model. The mathematical model uses terminal voltage inputs to calculate $d q$ current output, which is then converted back to line currents prior to rectification. This provides the diode modelling package, SimPowerSystems, with time varying generator currents.

In order to give current output, the machine model must relate the voltages in the $d q$ reference frame to the machine terminal quantities. The Clarke transform for the three-phase machine is well documented and is used in the power invariant form shown in (6).

$$
\left[\begin{array}{l}
V_{d} \\
V_{q} \\
V_{0}
\end{array}\right]=\sqrt{\frac{2}{3}}\left[\begin{array}{ccc}
1 & -0.5 & -0.5 \\
0 & -\frac{\sqrt{3}}{2} & \frac{\sqrt{3}}{2} \\
\frac{1}{\sqrt{2}} & \frac{1}{\sqrt{2}} & \frac{1}{\sqrt{2}}
\end{array} \mid\left[\begin{array}{c}
V_{a} \\
V_{b}
\end{array} \mid\right.\right.
$$

The Park transform simplifies the simulation by removing the angular dependence of the coil linkages, giving the standard $d q$ model in the synchronous reference frame; this reduces computation time.

The machine equations are given in (7) as a function of the machine $d q$ voltages in the synchronous reference frame.

$$
\begin{aligned}
& V_{d s}=i_{d s} R_{s}+L_{d} \frac{d i_{d s}}{d t}+L_{m d}\left(\frac{d i_{k d}}{d t}+\frac{d i_{f d}}{d t}\right)-\omega_{r}^{e}\left(L_{q} i_{q s}+L_{m q} i_{k q}\right) \\
& V_{q s}=i_{q s} R_{s}+L_{q} \frac{d i_{q s}}{d t}+L_{m q} \frac{d i_{k q}}{d t}+\omega_{r}^{e}\left(L_{d} i_{d s}+L_{m d}\left(i_{k d}+i_{f d}\right)\right) \\
& 0=i_{k d} R_{k d}+L_{k d} \frac{d i_{k d}}{d t}+L_{m d}\left(\frac{d i_{d s}}{d t}+\frac{d i_{f d}}{d t}\right) \\
& 0=i_{k q} R_{k q}+L_{k q} \frac{d i_{k q}}{d t}+L_{m q} \frac{d i_{q s}}{d t} \\
& V_{f d}=i_{f d} R_{f d}+L_{f d} \frac{d i_{f d}}{d t}+L_{m d}\left(\frac{d i_{d s}}{d t}+\frac{d i_{k d}}{d t}\right) \\
& T_{e}=p p \cdot\left(\varphi_{d} i_{q}-\varphi_{q} i_{d}\right)
\end{aligned}
$$

Implementation in MATLAB Simulink can be achieved by arranging the equations in state-space form, enabling current output.

$$
\underset{\sim}{i}=\left\lceil\left(\lceil D\rceil^{-1} \underset{\sim}{v}-\lceil R\rceil^{-1}\lceil\Delta\rceil \underset{\sim}{i}\right) d t\right.
$$

where $A$ is a combined matrix of resistance and rotational dependent components and $B$ is a constant matrix of self and mutual inductances, which can be inverted in a pre-processor script. 
Assumptions are made within the model to enable the generator characteristics to be analysed. Windings are assumed to be sinusoidally distributed so that the air-gap flux is also sinusoidal. Superposition is applied, through linear magnetic circuits, disregarding saturation effects, and saliency terms higher than twice the rotational air-gap frequency are neglected. Zero-sequence components are considered within the model through their interaction with the zero-sequence path stator leakage terms; higher order harmonic terms map to either the fundamental $d q$ or zerosequence circuits.

The generator $d q$ currents are rectified using diodes modelled within the SimPowerSystems library. Current sources are used to provide the $\mathrm{AC}$ input to the rectifier, with measured $\mathrm{AC}$ voltages acting as a feedback path within the model, highlighted in Figure 5. The model includes high value resistors for diode snubbing and to define a virtual star point for measurements, but has no capacitors.

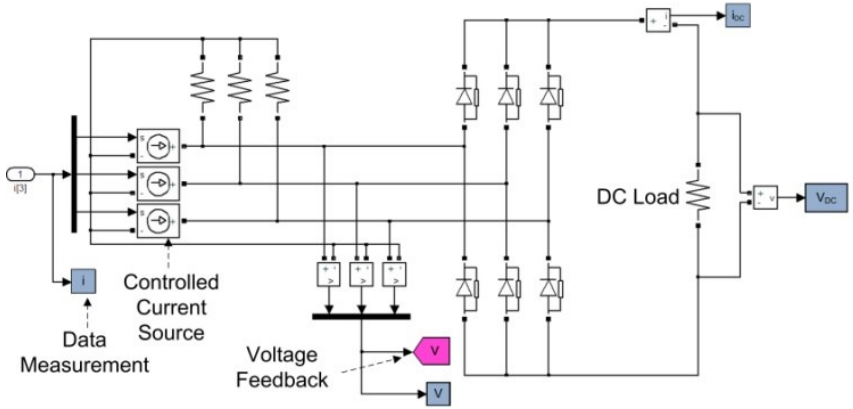

Figure 5 SimPowerSystems diode rectification stage

Validation of the three-phase mathematical model has been completed through experimental testing on the starconnected machine modelled. The simulation results proved to be consistent with the physical test data, as highlighted by generator output current and voltage depicted in Figure 6, and also the DC voltage in Figure 7.

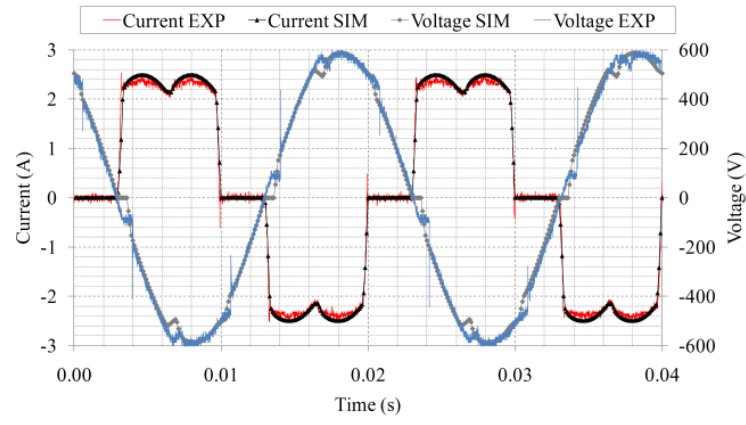

Figure 6 Generator output AC voltage and current

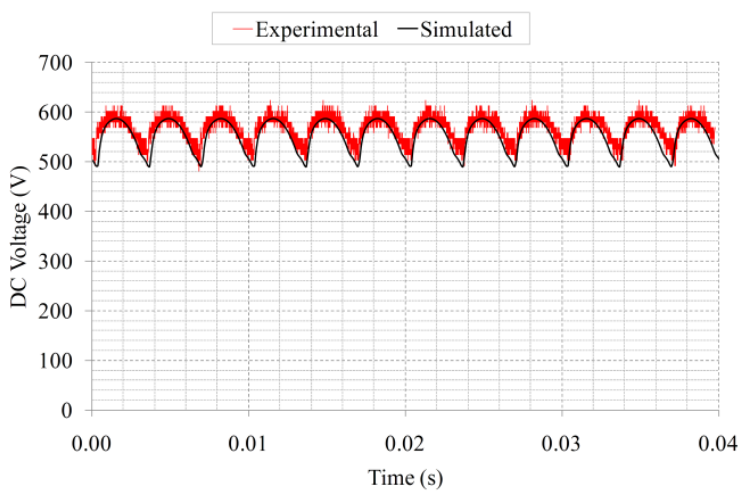

Figure 7 DC voltage rectifier output

Verification of the mathematics allows the extension to the multiphase case, which requires the modification of the Clarke transform (retaining power invariance) to include the increased number of phases [13].

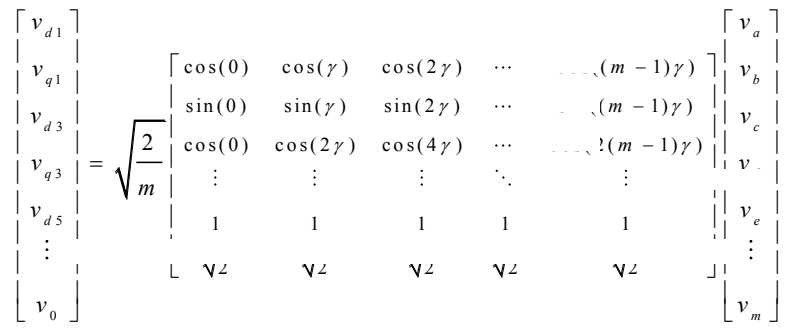

where $\gamma$ is the phase displacement in radians, $m$ is the number of phases; subscripts denote conventional $a b c$ phase notation and $d q$ voltages, with higher harmonic numbers occurring in $d q$ axis pairs.

The harmonic and zero-sequence leakage path becomes more complex as a result of the phase extension; this encompasses the higher order $d q$ axis pairs of harmonics and single zero-sequence path for an odd phase number machine.

$$
i_{0}=\frac{1}{L_{l s}} \int\left(v_{0}-R_{s} i_{0}\right) d t
$$

where $i_{0}$ is the zero-sequence current, $v_{0}$ is the zerosequence voltage, $R_{s}$ is the stator resistance and $L_{l s}$ denotes the stator leakage inductance.

\section{Simulation Results}

The mathematical modelling is conducted on odd phase number machines. The utilisation of pre-processor scripting allows the machine parameters to be changed with relative ease, therefore, simplifying the simulation for a variable number of phases. The benefit of this approach is that phase number can be expanded and investigated using a straightforward approach; for this instance 3, 5, 7, 9 and 11 phase machines will be compared. This paper focuses on comparing the simulation results across these phases, for both star- and delta-connected machines, investigating generator current and harmonic content, and DC ripple voltage reduction with increased phase number. For the starconnected case, the DC load current was scaled in proportion 
to the number of phases; this ensured the same power was drawn from generator in each case. Fixed field voltage input was imposed on each model to remove the automatic voltage regulation (AVR) control loop behaviour.

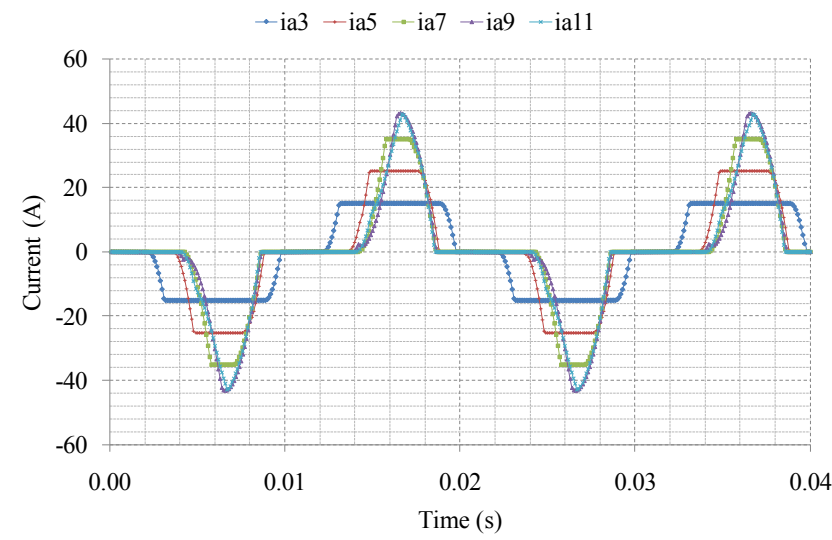

Figure 8 Star-connected AC current in one generator phase for increasing phase number

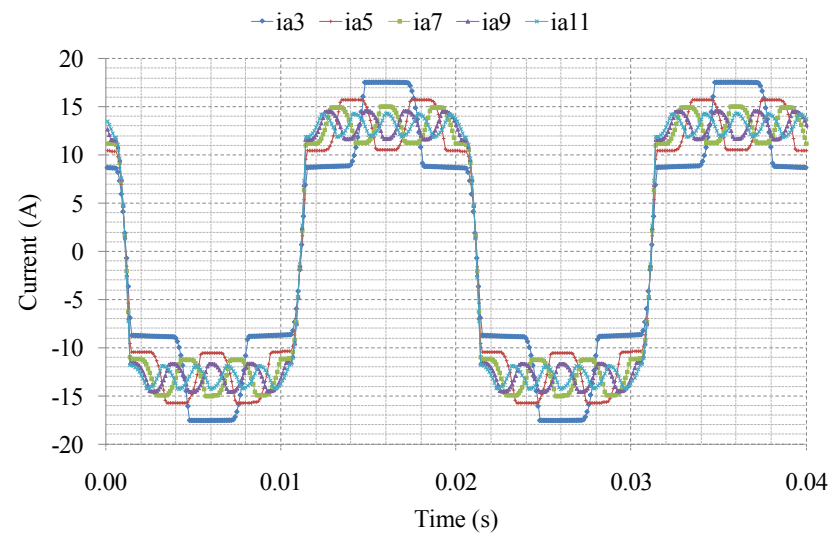

Figure 9 Delta-connected AC current in one generator phase for increasing phase number

Distinct differences in peak current magnitude and shape can be observed between the star-connected and deltaconnected synchronous generator outputs, depicted in Figure 8 and Figure 9, respectively. Both generators give the same power. The scaling of load current in the starconnected machine (to maintain a constant generator output power) results in a high peak current with a poor form factor. With nine and eleven phases, diode commutation is not complete within the $\pi / 2 m$ radians, and more than two phases conduct at any time, giving a triangular current pulse rather than a quasi-square waveform. The commutation angle increases with number of phases for the star-connected generator, because of the increase in peak current and remains constant for the delta-connected system, which has a fixed DC current.

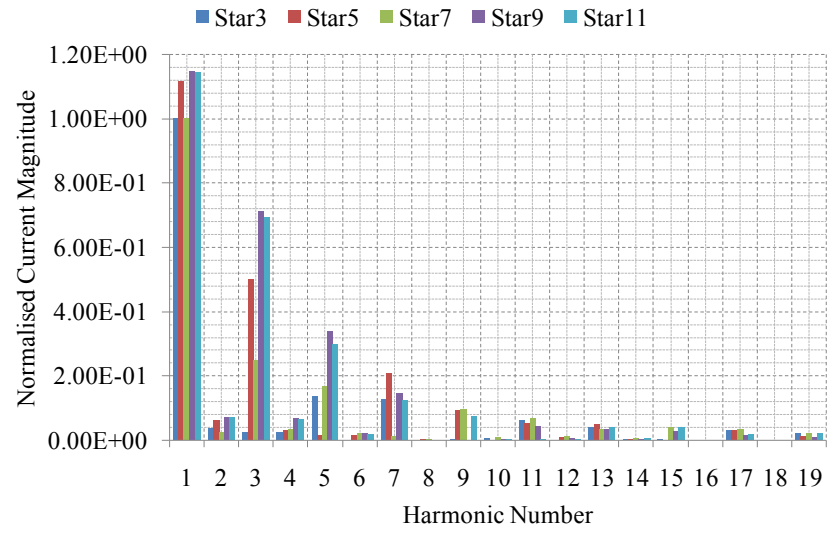

Figure 10 Harmonic content of star-connected generator current, normalised with respect to the three-phase fundamental.

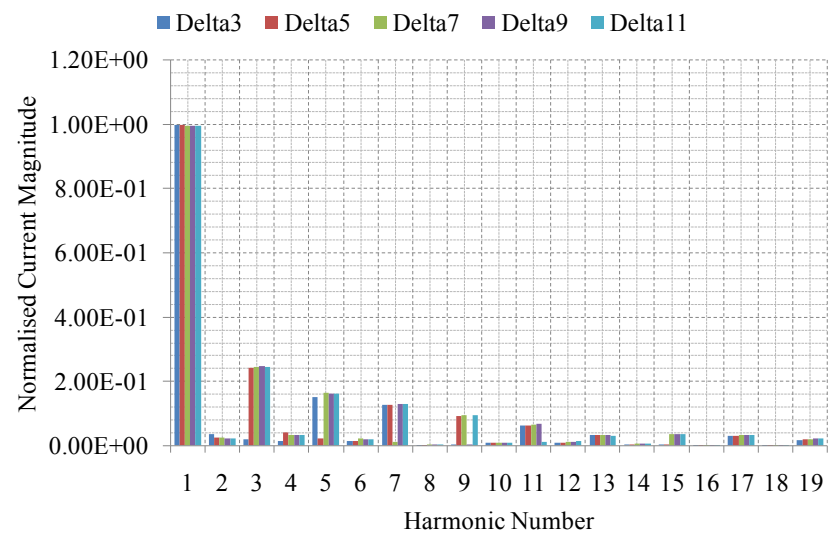

Figure 11 Harmonic content of delta-connected generator current, normalised with respect to the three-phase fundamental.

The normalised harmonics, shown in Figure 10 for the star-connected generator, reflect the poor form factor of the waveform, with a higher proportion of low-frequency harmonics. As expected, since the delta-connected machine exhibits $180^{\circ}$ conduction the magnitude of the $n^{\text {th }}$ current harmonic in Figure 11 approximates the $1 / n$ relationship of a square wave.

As predicted by the analysis, for a star-connected machine, there is a decrease in rectified DC voltage as number of phases is increased. It would be possible to redesign the generator with a different turns ratio, to maintain the same DC voltage as in the three-phase case. However, the ratio of load current to peak generator current would not change, as the generator current rating will reduce if the number of turns is increased. When delta-connected, the DC voltage remains relatively constant as phase number increases; as illustrated in Figure 12 and Figure 13. 


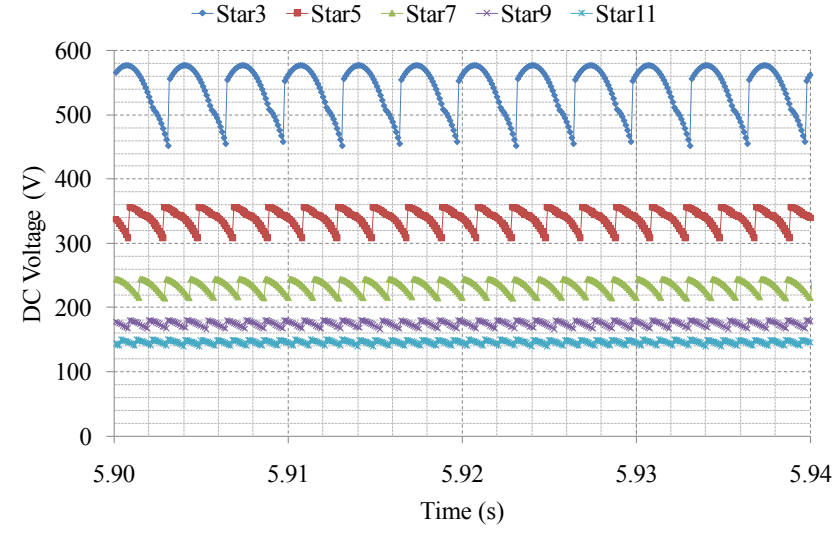

Figure 12 DC voltage output for star-connected machine

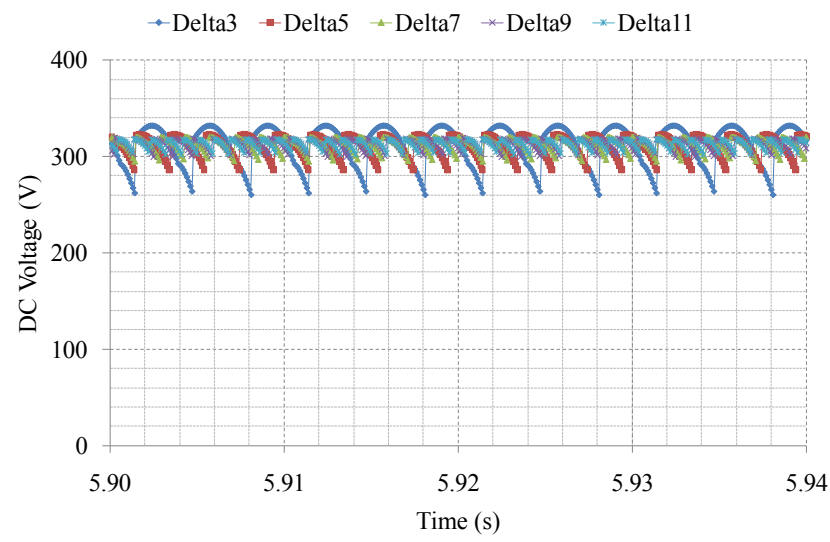

Figure 13 DC voltage output for delta-connected machine

The magnitude of the ripple within the DC voltage output is of particular importance when considering aerospace applications in facilitating the removal of filter capacitance. The reduction in ripple is similar in both the star-connected and delta-connected cases, as highlighted in Table II. Even though the effects of commutation have been included, the ripple voltage is higher than predicted, which may be due to the dynamics of the rotor circuits. The peak DC voltage is over-predicted, which is partly due to the omission of the stator resistance term and partly due to the reduction of voltage during commutation. Table II shows good agreement between simulation and analysis, in terms of average DC voltage and $\mathrm{AC}$ currents. It should be noted that in the nine and eleven phase star-connected modes, predicted values have been omitted, since the analysis does not cover the case where more than three diodes conduct simultaneously.
TABLE II COMPARISON OF DC VOLTAGE AND AC CURRENT FOR A GENERATOR RECTIFIER SYSTEM; $\mathrm{S}=$ SIMULATED; $\mathrm{P}=$ PREDICTED

\begin{tabular}{|c|c|c|c|c|c|c|}
\hline Phase Number & & 3 & 5 & 7 & 9 & 11 \\
\hline \multicolumn{7}{|c|}{ Star } \\
\hline \multirow[t]{2}{*}{ Average DC voltage $\mathrm{V}$} & $\mathrm{S}$ & 540.0 & 339.0 & 233.0 & 174.6 & 145.9 \\
\hline & $\mathrm{P}$ & 542.8 & 340.1 & 230.6 & & \\
\hline \multirow[t]{2}{*}{ Peak DC voltage } & $\mathrm{S}$ & 577.4 & 356.3 & 244.1 & 180.3 & 150.2 \\
\hline & $\mathrm{P}$ & 580.3 & 381.7 & 280.0 & 219.5 & 180.5 \\
\hline \multirow[t]{2}{*}{ Pk-Pk ripple \% } & $S$ & 23.4 & 14.0 & 12.5 & 7.7 & 7.1 \\
\hline & $\mathrm{P}$ & 16.4 & 10.7 & 12.0 & & \\
\hline \multirow[t]{2}{*}{ Peak AC current A } & $\mathrm{S}$ & 15.2 & 25.1 & 35.1 & 43.1 & 42.8 \\
\hline & $P$ & 15.0 & 25.0 & 35.0 & 45.0 & 55.0 \\
\hline \multirow[t]{2}{*}{ RMS AC current A } & $S$ & 12.2 & 15.2 & 17.3 & 17.9 & 17.5 \\
\hline & $\mathrm{P}$ & 12.2 & 15.8 & 18.7 & & \\
\hline \multirow[t]{2}{*}{ Commutation angle rad } & $\mathrm{S}$ & 0.25 & 0.35 & 0.44 & & \\
\hline & $\mathrm{P}$ & 0.20 & 0.32 & 0.44 & 0.56 & 0.69 \\
\hline \multicolumn{7}{|c|}{ Delta } \\
\hline \multirow[t]{2}{*}{ Average DC voltage $\mathrm{V}$} & $\mathrm{S}$ & 310.8 & 311.0 & 312.0 & 312.3 & 312.6 \\
\hline & $\mathrm{P}$ & 312.4 & 312.4 & 312.6 & 312.4 & 311.9 \\
\hline \multirow[t]{2}{*}{ Peak DC voltage } & $\mathrm{S}$ & 332.3 & 322.7 & 320.3 & 319.0 & 318.0 \\
\hline & $P$ & 332.5 & 323.5 & 321.2 & 320.4 & 319.9 \\
\hline \multirow[t]{2}{*}{ Pk-Pk ripple \% } & $\mathrm{S}$ & 23.3 & 11.7 & 8.1 & 6.3 & 5.1 \\
\hline & $\mathrm{P}$ & 16.8 & 7.5 & 5.0 & 4.0 & 3.5 \\
\hline \multirow[t]{2}{*}{ Peak AC current A } & $\mathrm{S}$ & 17.6 & 15.7 & 15.0 & 14.6 & 14.3 \\
\hline & $\mathrm{P}$ & 17.3 & 15.6 & 14.8 & 14.4 & 14.2 \\
\hline \multirow[t]{2}{*}{ RMS AC current A } & $\mathrm{S}$ & 12.2 & 12.6 & 12.7 & 12.7 & 12.7 \\
\hline & $\mathrm{P}$ & 12.2 & 12.7 & 12.9 & 12.9 & 12.9 \\
\hline \multirow[t]{2}{*}{ Commutation angle rad } & $\mathrm{S}$ & 0.25 & 0.25 & 0.25 & 0.25 & 0.25 \\
\hline & $\mathrm{P}$ & 0.22 & 0.22 & 0.22 & 0.22 & 0.22 \\
\hline
\end{tabular}

\section{PERFORMANCE IMPLICATIONS}

This section explores the trade-offs between reductions in DC voltage ripple, and increases in peak generator currents, stator Joule losses and damper currents for different phase numbers, for a constant generator power.

Table III shows copper loss and torque values from the simulation. The generator speed was held constant and skin effects have been neglected. Under these conditions, simulated damper losses are small anyway and decrease as the number of phases is increased. There are no significant differences in torque pulsations between the star and delta cases and torque ripple also decreases at higher phase numbers. This is expected, since [14] shows that for balanced sinusoidal windings, only supply harmonics of order $2 m \pm 1$ create torque or induce rotor currents.

In contrast, the stator losses increase as the number of phases is increased and this is most significant for the starconnection. From Table II, it can be seen that the peak current increases excessively in the star-connected case. 
TABLE III SIMULATED POWER AND TORQUE VALUES FOR A GENERATOR RECTIFIER SYSTEM

\begin{tabular}{|l|r|r|r|r|r|}
\hline Phase Number & $\mathbf{3}$ & $\mathbf{5}$ & $\mathbf{7}$ & $\mathbf{9}$ & \multicolumn{1}{c|}{$\mathbf{1 1}$} \\
\hline \multicolumn{7}{|c|}{ Star } \\
\hline Stator loss W & 189.5 & 298.0 & 383.4 & 410.8 & 393.6 \\
\hline d-axis damper loss W & 2.81 & 0.51 & 0.02 & 0.01 & 0.01 \\
\hline q-axis damper loss W & 1.07 & 0.31 & 0.04 & 0.01 & 0.01 \\
\hline Torque ripple Nm & 4.81 & 1.995 & 1.193 & 0.576 & 0.437 \\
\hline \multicolumn{7}{|c|}{ Delta } \\
\hline Stator loss W & 190.7 & 203.4 & 206.7 & 207.9 & 208.5 \\
\hline d-axis damper loss W & 2.79 & 1.14 & 0.53 & 0.24 & 0.10 \\
\hline q-axis damper loss W & 1.06 & 0.40 & 0.19 & 0.09 & 0.04 \\
\hline Torque ripple Nm & 4.81 & 1.995 & 1.184 & 0.779 & 0.528 \\
\hline
\end{tabular}

Using the expressions in Table I, it is possible to calculate indicators of DC voltage and AC current quality for increasing numbers of phases, as shown in Figure 14. Commutation effects have been neglected in these graphs to allow a non-machine-specific comparison. The figure confirms the increase in RMS stator currents, and excessive generator peak currents for the star-connected case with little or no change for the delta-connection. DC ripple is the same for both connection methods.

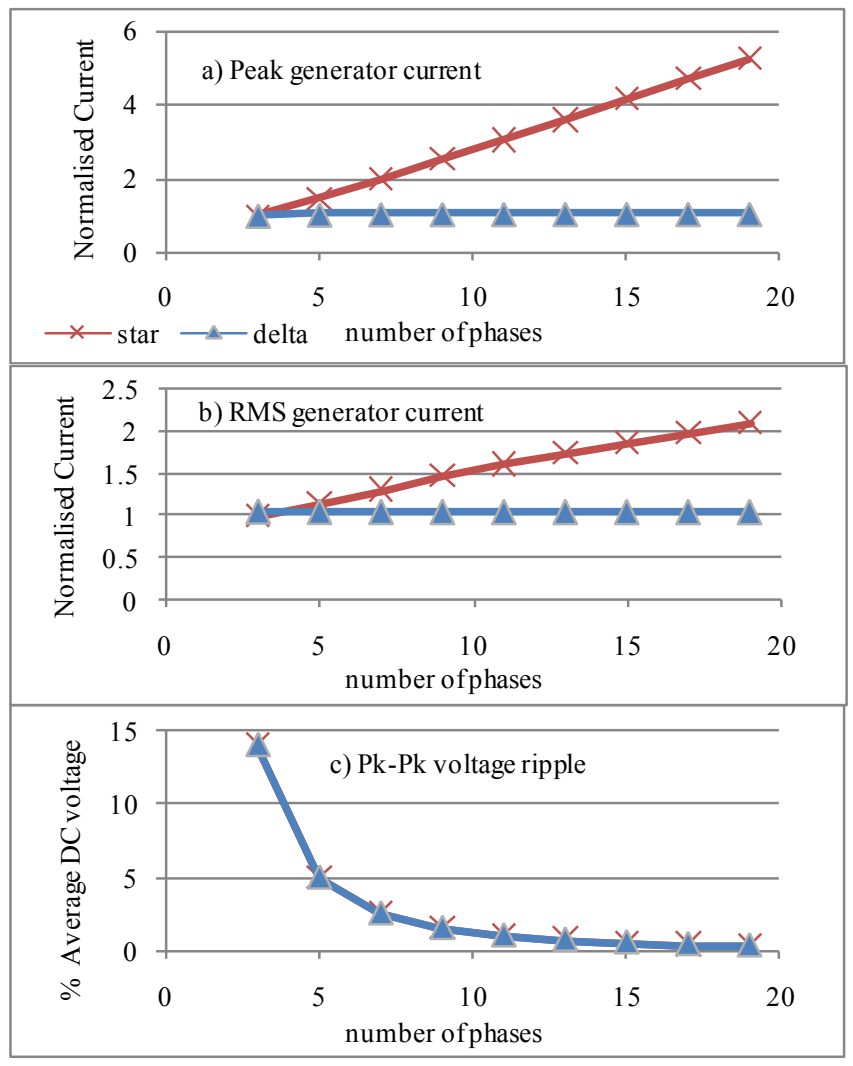

Figure 14 Comparison of Generator current and DC voltage ripple as the number of phases is increased.
The excessive peak currents in the star-connected case are of particular concern because iron loss depends on peak flux. Calculation of iron loss requires knowledge of the machine geometry and steel properties but would also be expected to be excessive.

The performance of the delta-connected machine is generally better, because the rectifier voltage remains constant as the number of phases is increased, keeping the current at close to its nominal value. However, in the event of an open-circuit fault one of the parallel paths in the generator is not available. This will reduce the generator current rating by one half, increase the voltage ripple and reduce the average voltage, severely limiting the system performance.

\section{CONCLUSIONS AND FURTHER WORK}

With both connection methods, a multiphase generator and uncontrolled diode rectifier can be used to give a lowripple DC voltage output. Torque ripple and damper losses can also be reduced by increasing the number of phases. However, there is an upper limit to the number of phases that can be used, before the commutation time exceeds the diode on-time. This depends on the generator leakage inductance and maximum load current.

In the star-connected case, this comes at the cost of excessive peak generator currents and increased generator losses, which makes operation with a high number of phases unviable. In the delta-connected case, the generator currents are much more acceptable, although there is a minimal increase in stator losses, due to the current harmonics present. However, the rectifier diodes must be rated for the DC load current, which is approximately twice the generator peak current. This solution is particularly interesting for permanent magnet generators with a trapezoidal back emf, which are designed for square-wave currents. However, since all phases of the generator conduct simultaneously, the tolerance of the delta-connected configuration to opencircuit faults is compromised.

As an alternative to an uncontrolled diode rectifier, an active rectifier can be used to draw unity power factor, sinusoidal generator currents. This maximises generator efficiency, but increases complexity and introduces voltage harmonics onto the DC link.

\section{LIST OF SYMBOLS}

$V_{a}$ - Conventional phase notation

$V_{d l}$ - Fundamental d-axis voltage

$V_{d 3}$ - Third harmonic of d-axis voltage

$V_{d c}$ - DC voltage

$V_{0} \quad$ - Zero-sequence voltage

$V_{d s}$ - d-axis voltage in the synchronous reference frame

$i_{d s}$ - d-axis current in the synchronous reference frame

$I_{d c} \quad$ - DC current 
$L_{d} \quad$ - d-axis inductance

$L_{a d}$ - winding inductance phases a to rotor d-axis

$L_{a n}$ - winding inductance, phases a to $\mathrm{n}$

$L_{a q}$ - winding inductance, phases a to rotor q-axis

$L_{f d} \quad$ - d-axis field winding inductance

$L_{m d}$ - d-axis magnetising inductance

$L_{k d}$ - d-axis damper winding inductance

$L_{m q}$ - q-axis magnetising inductance

$L_{l s} \quad$ - Stator leakage inductance

$\omega_{r}^{e}$ - Rotational speed (electrical)

$T_{e} \quad$ - Electromechanical torque

$\varphi_{d} \quad$ - d-axis flux linkage

y $\quad$ - Instantaneous voltage

$m$ - Number of phases

$\gamma \quad$ - Phase displacement angle

$R_{s} \quad$ - Stator resistance

\section{ACKNOWLEDGMENTS}

The authors would like to acknowledge the support of the UK Engineering and Physical Sciences Research Council and Rolls-Royce PLC. The authors would also like to extend their gratitude to Cummins Generator Technologies UK for their donation of test equipment.

\section{REFERENCES}

[1] M. Hirst, A. McLoughlin, P. J. Norman, and S. J. Galloway, "Demonstrating the more electric enigine: a step towards the power optimised aircraft," IET Electric Power Applications, vol. 5, pp. 3 13, 2011.

[2] I. Moir and A. Seabridge, Aircraft Systems, 3rd ed.: John Wiley \& Sons Ltd, 2008.

[3] R. Todd and A. J. Forsyth, "DC-bus power quality for UAV systems during generator fault conditions," in 5th IET International
Conference on Power Electronics, Machines and Drives, pp. 1-6, , 2010.

[4] N. N. Schulz, M. Lin, and A. K. Srivastava, "A Generic Digital Model of Multiphase Synchronous Generator for Shipboard Power System," in Electric Ship Technologies Symposium, Arlington, VA, USA, 2007, pp. 348-355.

[5] L. Parsa, "On Advantages of Multiphase Machines," IEEE Industrial Electrical Conference, pp. 1574-1579, 6th November 2005.

[6] A. Oliver, A. C. Smith, M. Husband, M. Bailey, and Y. Feng, "Assessment of Small Bend Diameter Magnesium Diboride Wire for a Superconducting Fault Current Limiter Application," IEEE Transactions on Applied Superconductivity, vol. 19, 5th June 2009.

[7] Jeff Buckley, "Future Trends in Commercial and Military Shipboard Power Systems", 2002 IEEE Power Engineering Society Summer Meeting (Cat. No.02CH37376), p 340-2 vol.1, 2002

[8] S. D. Sudhoff, and Wasynczuk, O, "Analysis and Average-Value Modeling of Line-Commutated Converter - Synchronous Machine Systems," IEEE Transactions on Energy Conversion, vol. 8, pp. 9298, 1993

[9] A. Cross, A. Baghramian, A. J. Forsyth, "Approximate, average, dynamic models of uncontrolled rectifiers for aircraft applications", IET Power Electronics, v 2, n 4, p 398-409, July 2009

[10] I. Boldea, "The Electrical Generators Handbook: Synchronous Generators", CRC Press, Boca Raton FL, 2006.

[11] Ned Mohan, Tore Undeland, William Robbins, "Power electronics : converters, applications, and design”, Wiley, 2002.

[12] V. Zozulin, "Calculation of currents and voltages for multiphase synchronous generators with bridge-rectifier load", Elektrotekhnika, vol51, No 5, pp10-13, 1980.

[13] D. C. White and H. H. Woodson, "Electromechanical Energy Conversion”. New York: John Wiley \& Sons, Inc., 1959.

[14] S. Williamson and S. Smith, "Pulsating Torque and Losses in Multiphase Induction Machines", IEEE Transactions on Industry Applications, Vol. 39, no. 4, pp. 986-993, Aug. 2003. 